\title{
Attenuation of Ketamine Effects by Nimodipine Pretreatment in Recovering Ethanol Dependent Men: Psychopharmacologic Implications of the Interaction of NMDA and L-Type Calcium Channel Antagonists
}

Evegeny M. Krupitsky, M.D., Ph.D., Andrey M. Burakov, M.D., Ph.D., Tatyana N. Romanova, Ph.D., Nina I. Grinenko, M.D., Alexander Y. Grinenko, M.D., Ph.D., Jason Fletcher, M.A., Ismene L. Petrakis, M.D., and John H. Krystal, M.D.

Ketamine blocks the calcium channel associated with $\mathrm{N}$-methyl-D-aspartate (NMDA) glutamate receptors. It has transient behavioral effects in healthy humans that resemble aspects of schizophrenia, dissociative disorders, and ethanol intoxication. Ethanol is an antagonist of both $N M D A$ receptors and L-type voltage-sensitive calcium channels (VSCC) and it has minimal psychotogenic activity in humans. A double-blind placebo-controlled study was conducted that evaluated whether pretreatment with the L-type VSCC antagonist, nimodipine, $90 \mathrm{mg} \mathrm{D}$, modulated ketamine response (bolus $0.26 \mathrm{mg} / \mathrm{kg}$, infusion of $0.65 \mathrm{mg} /$ $\mathrm{kg} / \mathrm{hr}$ ) in 26 ethanol-dependent inpatients who were sober for at least one month prior to testing. This study found that nimodipine reduced the capacity of ketamine to induce psychosis, negative symptoms, altered perception, dysphoria, verbal fluency impairment, and learning deficits.
Nimodipine improved memory function, but had no other intrinsic behavioral activity in this patient group. Nimodipine pretreatment attenuated the perceived similarity of ketamine effects to ethanol as well as ketamineinduced euphoria and sedation. However, nimodipine did not reduce the stimulant effects of ketamine. These data suggest that antagonism of L-type VSCCs attenuates the behavioral effects of NMDA antagonists in humans. They support the continued evaluation of nimodipine in the treatment of neuropsychiatric disorders. They also suggest that drugs, such as ethanol, that combine NMDA and L-type VSCC antagonism may have enhanced tolerability without attenuation of their stimulant effects.

[Neuropsychopharmacology 25:936-947, 2001] (C) 2001 American College of Neuropsychopharmacology. Published by Elsevier Science Inc.
From the Alcohol Research Center (116-A), VA Connecticut Healthcare System, 950 Campbell Ave., West Haven, CT 06516 (EMK, JF, ILP , JHK) and Department of Psychiatry, Yale University School of Medicine, New Haven, CT, USA (EMK, JF, ILP, JHK), and St. Petersburg Scientific-Research Center of Addictions and Psychopharmacology, St. Petersburg, Russia (EMK, AMB, TNR, NIG, AYG).

Address correspondence to: Alcohol Research Center (116-A) VA Connecticut Healthcare System 950 Campbell Ave. West Haven, CT 06516, Tel.: (203) 937-4790, Fax: (203) 937-3468, E-mail: john.krystal @yale.edu

Received December 21, 2000; revised July 20, 2001; accepted August 5, 2001.

Online publication: $8 / 17 / 01$ at www.acnp.org/citations/ Npp080701161
KEY WORDS: Psychosis; Schizophrenia; Alcohol dependence; Glutamate; NMDA; L-type calcium channel; Ketamine; Nimodipine; Memory; Cognition; Intoxication; Alcoholism

$\mathrm{N}$-methyl-D-aspartate (NMDA) receptor antagonists have analgesic, anesthetic, anxiolytic, antiaddictive, anticonvulsant, antidepressant, antiparkinsonian, and neuroprotective actions (Krystal et al. 1999c). In addition, these drugs produce effects in healthy human subjects that resemble aspects of the signs and symptoms of schizophrenia or dissociative disorders (Krystal et al. 
1999a). As a result, ketamine administration may provide a laboratory-based approach that may contribute to the characterization of NMDA receptor contributions to cognitive function and the development of novel pharmacotherapeutic approaches that might ameliorate the consequences of NMDA receptor dysfunction.

NMDA receptor antagonists also have ethanol-like behavioral effects in animals and humans (Grant and Colombo 1993; Krystal et al. 1998b; Petrakis et al. 2001). In ethanol dependent patients, ketamine effects were deemed more similar to ethanol effects than they were to the effects of marijuana or cocaine (Krystal et al. 1998b). This observation is consistent with studies indicating that NMDA receptors are among the highest affinity targets of ethanol in the brain, where it produces dose-related uncompetitive antagonism of receptor function (Grant and Lovinger 1995; Lovinger 1997). In animals, the behavioral effects of ethanol have a complex neurobiology, reflecting the interaction of the many component dose-related actions of ethanol in the brain (Green and Grant 1998).

Ethanol, relative to the uncompetitive NMDA receptor antagonists phencyclidine and ketamine, has less propensity to produce psychotic symptoms in healthy humans or recovering ethanol-dependent patients (Krystal et al. 1994a; Krystal et al. 1998b; Luby et al. 1959). The limited psychotogenic propensity of ethanol at doses typically associated with human intoxication may reflect the capacity of ethanol facilitation of $\mathrm{GABA}_{\mathrm{A}}$ receptor function to moderate its NMDA antagonist effects (Grant and Lovinger 1995). Consistent with this hypothesis, some reduction in the perceptual effects of ketamine in healthy human subjects was produced by lorazepam pretreatment (Krystal et al. 1998a). However, preclinical data suggest that the capacity of ethanol to block L-type VSCCs (Crews et al. 1996) may also protect against its psychotogenic potential. In animals, components of the behavioral and discriminative stimulus effects of NMDA antagonists are attenuated by pretreatment with L-type VSCC antagonists (Green and Grant 1999; Green-Jordan and Grant 2000; Popoli et al. 1992; Sukhotina et al. 1999).

The current study evaluated the capacity of pretreatment with the L-type VSCC antagonist, nimodipine, to attenuate the cognitive and behavioral effects of the NMDA receptor antagonist, ketamine, in recently detoxified ethanol-dependent inpatients. This group of research subjects was selected because their experience increased the face validity and clinical importance of the ethanol-like subjective effects assessed.

\section{METHODS}

\section{Research Subjects}

This study was approved by the Internal Review Board of the Leningrad Regional Center of Addictions, St. Pe- tersburg, Russia and the Human Subjects Subcommittee of the VA Connecticut Healthcare System, West Haven, Connecticut, USA. Subjects participating in this study were identified from admissions to the inpatient programs of the Leningrad Regional Center of Addictions (Leningrad Regional Dispensary of Narcology), Leningrad Region, Russia. Due to recent controversy surrounding international collaborative research studies, we would like to outline the informed consent process in greater detail than is typical in published reports in the space below. The decision to enroll patients in testing was a multidisciplinary process that involved members of the clinical and research staff. When feasible, family members of the research subject were involved. All patients gave informed written consent to participate in the study prior to screening and testing and they were paid $\$ 3.50$ (US) per test day for their participation. The consent form was a translation of the consent form that had been approved in the USA and it was administered to potential research subjects in their native language (Russian). The consent form was designed to be understood by individuals with a grammar school education. The consent form clearly outlined the voluntary status of the research study, alternatives to participating in this research study, the fact that a decision to refrain from participating would not influence subsequent treatment, and it indicated that subjects could withdraw from the study at any time. Subjects were warned that ketamine was a drug that has been abused and that it might stimulate alcohol craving. Subjects were advised not to participate if they were concerned about the abuse potential of ketamine or about an adverse impact of ketamine administration on their recovery from alcoholism.

Twenty-six male inpatients (mean \pm standard error of the mean (SEM) for age $\pm 38.7 \pm 1.6$ years) who met ICD-X /DSM-IV criteria for alcohol dependence, as determined by the Structured Clinical Interview for ICD-X, participated in testing. Patients began heavy drinking at $28.2 \pm 1.1$ years of age. Patients had a $10.5 \pm 1.1-$ year history of ethanol abuse. In the week prior to admission, patients reported that their average daily consumption of ethanol was the equivalent of $598.1 \pm 63.4$ cc (range: $200-1500$ cc) of $40 \%$ ethanol. Patients were medically stable at study entry based on medical history, physical examination, and routine laboratory testing. Also, they did not make criteria for another ICD-X/ DSM-IV psychiatric or substance abuse or dependence diagnoses (other than nicotine dependence) in the year prior to testing. Prior to testing, patients had been sober for more than 30 days and they were $40.7 \pm 1.9$ days from their last dose of benzodiazepines administered for the purposes of ethanol detoxification. Patients were recruited from the inpatient treatment unit and they remained on the inpatient unit for the duration of the study. 


\section{Drug Administration}

Patients completed four test days (one test day per week over a minimum of four weeks) in a randomized and balanced order under double blind conditions during which they received nimodipine $90 \mathrm{mg}$., p.o. or matched placebo tablets (Baeyer, Inc., West Haven, CT) every six hours beginning $18 \mathrm{~h}$ prior to the testing procedure and on the test day $3 \mathrm{~h}$ prior to the administration of ketamine hydrochloride (Calipsol, Gedeon Rihter, Inc., Hungary) or saline infusion. This study employed this extended nimodipine pretreatment paradigm as an attempt to compensate partially for the limited central nervous system bioavailability of nimodipine (Carcas et al. 1996). Ketamine was administered as a 1-min intravenous bolus of $0.25 \mathrm{mg} / \mathrm{kg}$ followed by a 1-hour intravenous infusion of $0.5 \mathrm{mg} / \mathrm{kg}$. Thus, the four test days consisted of: 1) placebo nimodipine followed by placebo ketamine (placebo test day), 2) placebo nimodipine and active ketamine (ketamine test day), 3) active nimodipine and active ketamine (nimodipine-ketamine test day), and 4) active nimodipine and placebo ketamine (nimodipine test day).

\section{Behavioral Ratings}

Symptoms and behavioral characteristics of schizophrenia were assessed using the Brief Psychiatric Rating Scale (BPRS; Overall and Gorham 1962). As in previous studies from our group (Anand et al. 2000; Krystal et al. 1999b; Krystal et al. 1998a; Krystal et al. 1994a) psychosis was assessed using the four key positive symptoms from the BPRS: (conceptual disorganization, hallucinatory behavior, suspiciousness, and unusual thought content) and negative symptoms were assessed using three key items (blunted affect, emotional withdrawal, and motor retardation). Dysphoric mood responses were assessed using the anxious depression factor derived from the BPRS (anxiety, guilt feelings, depressive mood, somatic concern, tension, and motor retardation; (Hedlund and Vieweg 1980). The BPRS was administered prior to ketamine administration (-60 min), and 5, 35, 85, 120, and $210 \mathrm{~min}$ following the initiation of ketamine infusion. Ratings assessed the period following the previous assessment. Thus, the 35-min timepoint reflected the previous thirty minutes.

The Clinician-Administered Dissociative States Scale (CADSS; (Bremner et al. 1998)) was a clinician-administered measure of perceptual, behavioral, and attention alterations occurring during dissociative experiences which had been validated in healthy subjects, schizophrenic patients and patients with post-traumatic stress disorder. The scale involved 19 self-reported questions and 8 observer ratings scored from 0 (not at all) to 4 (extremely). The CADSS was administered at the $-60,60$,
85, 120, and 210 timepoints. Similar results were obtained with both the self-rated and observer-rated components, so only the observer-rated subscale data are reported.

Data are reported from three measures of ethanollike subjective effects: self- rated visual analog scale measuring similarity to acute behavioral effects of alcohol $(0=$ not at all similar, $100=$ identical $)$; a scale measuring the volume (in cc) of a typical distilled beverage ( $40 \%$ ethanol) that would be expected to produce the level of intoxication experienced by the subject (Comparable Volume of Ethanol Scale) (Krystal et al. 1998b); and the Biphasic Alcohol Effects Scale (BAES) (Martin et al. 1993). The BAES has seven self-rated items assessing stimulant effects associated with the ascending blood ethanol limb of human ethanol intoxication and seven items assessing sedative effects associated with the descending blood ethanol limb of human ethanol intoxication. These scales were administered at $-60,5$, 35,105 , and 210 timepoints. Subjects also completed a $100 \mathrm{~mm}$ visual analog scale measuring euphoria ("high") that has been employed in previous studies (Krystal et al. 1998b; Krystal et al. 1994b) at the -60, 5, 35, 105, 150, 180, and 210-min timepoints.

Attention and memory were assessed in this study using a verbal fluency task and the Hopkins Verbal Learning Test. In the verbal fluency test (Borkowski et al. 1967), individuals generated as many words as possible beginning with a designated letter within a oneminute interval. Different letters were identified on each test day at the 5-min timepoint and letters were chosen on the basis of comparable frequency within the Russian language. Learning and memory were assessed using the Hopkins Verbal Learning Test (HVLT) (Brandt 1991). In this task, lists of ten words were presented at the $45 \mathrm{~min}$ timepoint of the each test day. Recall was then assessed immediately in three trials, following a 30-min delay, and following the exposure to stimulus cues (recognition). The word lists were developed on the basis of their comparable frequency and difficulty within the Russian language.

Systolic blood pressure, diastolic blood pressure, and heart rate were measured while reclining in bed at the $-60,35,60,85,105,120,180$, and 210 timepoints.

\section{Data Analysis}

Consistent with a recent study of ketamine effects from our laboratory (Anand et al. 2000), random effects (mixed regression) models constituted the primary data analytic strategy (SAS, Proc Mixed, SAS Institute, Inc.). These models contained fixed effects including time (when repeated measures were employed on a given test day), nimodipine (levels: placebo, nimodipine), and ketamine (levels: placebo, ketamine) and the random effect of subject. In all cases where multiple measures of 
the same construct or when post-hoc analyses were performed, Bonferroni adjustments were made to the level of significance.

\section{RESULTS}

\section{Psychosis, Mood, and Perception}

Brief Psychiatric Rating Scale (BPRS)Four Key Positive Symptoms. As reflected by the BPRS four key positive symptom score, ketamine produced transient psychotic symptoms in the recovering ethanol dependent patients that were attenuated by pretreatment by nimodipine, while nimodipine did not produce psychosis (see Figure 1). The mixed regression model applied to these data revealed highly significant interactions of ketamine and time effects $\left(\mathrm{F}_{5,575}=60.4, p=.0003\right)$ and ketamine, nimodipine and time effects $\left(\mathrm{F}_{6,575}=8.6, p=\right.$ .0003). Post-hoc comparisons revealed that ketamine increased scores significantly relative to the placebo test day (drug $X$ time interaction: $\mathrm{F}_{5,275}=35.7, p=.0002$ ) and the combination of ketamine and nimodipine (drug $\mathrm{X}$ time interaction: $\mathrm{F}_{5,275}=7.0, p=.0002$ ).

BPRS Three Key Negative Symptoms. As indicated by the BPRS three key negative symptom score, ketamine produced transient blunting of affect, withdrawal, and psychomotor retardation in the recovering ethanol dependent patients. The negative symptoms were attenuated by pretreatment by nimodipine, while nimodipine did not produce these symptoms (see Figure 1). The mixed regression model applied to these data revealed highly significant interactions of ketamine and time effects $\left(\mathrm{F}_{5,575}=35.4, p=.0003\right)$ and ketamine, nimodipine and time effects $\left(\mathrm{F}_{6,575}=7.3, p=.0003\right)$. Post-hoc comparisons revealed that ketamine increased scores significantly relative to the placebo test day (drug $X$ time interaction: $\left.\mathrm{F}_{5,275}=22.9, p=.0002\right)$ and the combination of ketamine and nimodipine (drug $\mathrm{X}$ time interaction: $\left.\mathrm{F}_{5,275}=5.2, p=.0002\right)$.

BPRS Anxiety and Depression. The BPRS anxiousdepression factor score data suggested that ketamine produced transient dysphoria in the recovering ethanol dependent patients that was attenuated by pretreatment by nimodipine, while nimodipine did not produce dysphoric mood (see Figure 1). The mixed regression model applied to these data revealed highly significant interactions of ketamine and time effects $\left(\mathrm{F}_{5,575}=41.5, p=.0003\right)$ and ketamine, nimodipine and time effects $\left(\mathrm{F}_{6,575}=10.6\right.$, $p=.0003$ ). Post-hoc comparisons revealed that ketamine increased scores significantly relative to the placebo test day (drug $X$ time interaction: $\mathrm{F}_{5,275}=29.9, p=.0002$ ) and the combination of ketamine and nimodipine (drug $X$ time interaction: $\mathrm{F}_{5,275}=9.1, p=.0002$ ).
Clinician-Administered Dissociative States Scale (CADSS)-Clinician Ratings. Perceptual effects of ketamine, as measured by the clinician-rated items of the CADSS, were attenuated by nimodipine pretreatment, while nimodipine did not produce perceptual changes by itself (Figure 1). The mixed regression model applied to CADSS data revealed highly significant interactions of ketamine and time effects $\left(\mathrm{F}_{4,475}=5.7, p=.0001\right)$ and ketamine, nimodipine and time effects $\left(\mathrm{F}_{5,475}=6.1, p=\right.$ .0001). Post-hoc analyses revealed that the ketamine test day differed from both the placebo (drug $X$ time interaction: $\left.\mathrm{F}_{4,225}=33.6, p=.0002\right)$ and the nimodipine-ketamine (drug $X$ time interaction: $F_{4,225}=6.1, p=.0002$ ) test days.

\section{Ethanol Related Measures}

Similarity to Ethanol. Ketamine $\left(\mathrm{F}_{1,475}=261.6, p=\right.$ $.0003)$ and to a much less extent, nimodipine $\left(\mathrm{F}_{1,475}=\right.$ $6.3, p=.03)$, produced effects that were rated as similar to ethanol on the visual analog scale measuring similarity of drug effects to ethanol (Figure 2). Nimodipine appeared to alter ketamine effects, as suggested by a significant interaction of the effects of ketamine, nimodipine, and time $\left(\mathrm{F}_{5,475}=3.2, p=.02\right)$ in the mixed regression analysis. Post-hoc comparisons confirmed that the placebo-ketamine test day differed from the placebo-placebo test day (drug X time: $\mathrm{F}_{4,225}=44.6, p=$ .0002). In contrast, the comparison of the placebo-ketamine and nimodipine-ketamine test days revealed a significant nimodipine effect $\left(\mathrm{F}_{1,225}=9.3, p=.01\right)$, but an insignificant nimodipine $X$ time interaction.

Comparable Volume of Ethanol Scale (CVES). The analysis of the intensity of ethanol intoxication data, assessed using the CVES (Figure 2), revealed that ketamine (ketamine $\mathrm{X}$ time interaction: $\mathrm{F}_{4,475}=57.3, p=.0003$ ) produced a level of intoxication associated with the consumption of large amounts of ethanol. However, the interaction of ketamine, nimodipine, and time did not reach significance. The peak ethanol-like effects during testing approached the intensity associated with the ingestion of $600 \mathrm{cc}$ of $40 \%$ ethanol. Post-hoc testing suggested that comparison of the placebo-ketamine test day and nimodipine-ketamine test day revealed a significant nimodipine effect $\left(\mathrm{F}_{1,225}=6.8, p=.003\right)$, but no significant nimodipine $\mathrm{X}$ time interaction. Thus, nimodipine pretreatment may have modestly modulated ketamine effects on this outcome. In terms of 15-cc "standard" ethanol drinks (Krystal et al. 1998b), the peak level of intoxication on each test day was: placeboplacebo day: $0.0 \pm 0.0$ drinks, placebo-ketamine day: $15.0 \pm 2.1$ drinks, nimodipine-ketamine day: $11.9 \pm 1.8$ drinks, nimodipine-placebo day: $0.3 \pm 0.2$ drinks. Adjusting for multiple comparisons, the placebo-ketamine test day was higher than all other test days $(p<.05)$. 

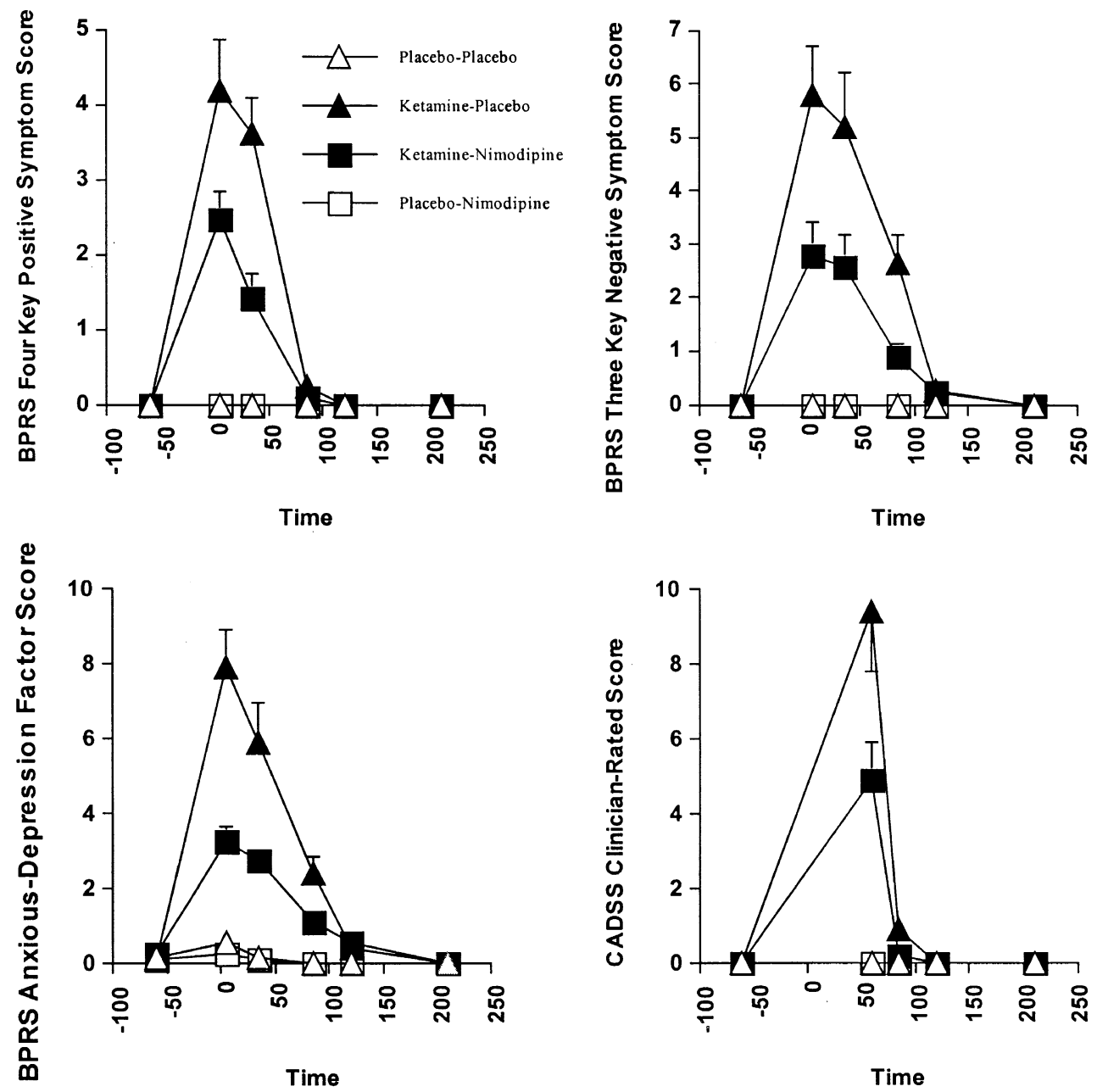

Figure 1. Nimodipine pretreatment decreased the capacity of ketamine administration to recovering ethanol-dependent patients $(n=26)$ to produce positive and negative symptoms associated with schizophrenia, dysphoric mood, and perceptual alterations associated with dissociative states. Top left panel: Brief Psychiatric Rating Scale (BPRS) four key positive symptom scores. Ketamine significantly increased positive symptoms and this effect was attenuated significantly by nimodipine pretreatment. Top right panel: BPRS 3 key negative symptom scores. Ketamine significantly increased negative symptoms and this effect was reduced significantly by nimodipine pretreatment. Lower left panel: BPRS anxious-depression factor scores. Ketamine increased dysphoric mood significantly as measured by the anxious-depression factor and this effect was blunted by pretreatment with nimodipine. Lower right panel: Clinician-administered dissociative state scale (CADSS) clinician ratings. These data indicated that ketamine produced perceptual alterations and this effect was decreased by nimodipine pretreatment. Nimodipine, by itself, did not have significant behavioral effects as measured by each of these four scales. Data presented represent mean data \pm standard error of the mean (SEM). Statistical analyses are presented in the text.

Thus analysis of the peak levels of intoxication as measured by the CVES produced results similar to the analysis of the complete data set.

Intensity of Ethanol-like Effects as Measured by the Biphasic Alcohol Effects Scale (BAES). An initial analysis of BAES was conducted in order to determine whether the BAES stimulant and sedative subscale scores were sensitive differentially to the interactive effects of ketamine and nimodipine. The mixed regression model applied to these data showed a significant interaction of ketamine, nimodipine, time, and BAES subscale $\left(\mathrm{F}_{5,975}=5.0, p=.0003\right)$. Based on this analysis, the stimulant and sedative subscales were analyzed separately and findings were adjusted for multiple comparisons.

In the recovering alcohol dependent patients, ketamine produced subjective effects, reflected in the BAES stimulant subscale scores, that resembled the stimulant effects associated with the ascending limb of ethanol intoxication (see Figure 3). The mixed regression model applied to these data revealed significant ef- 
fects of ketamine $\left(\mathrm{F}_{1,475}=57.1, p=.0002\right)$ and the ketamine $\mathrm{X}$ time interaction $\left(\mathrm{F}_{4,475}=20.8, p=.0002\right)$, but no other significant main effects or interactions.

On the BAES sedative subscale, ketamine produced effects that resembled the sedative effects associated with the descending limb of ethanol intoxication. The intensity of the sedative ethanol-like effects of ketamine was attenuated by nimodipine pretreatment even though nimodipine had no effects when administered by itself (see Figure 3). The mixed regression model applied to these data revealed highly significant interactions of ketamine and time effects $\left(\mathrm{F}_{4,475}=20.8, p=\right.$ .0002) and ketamine, nimodipine and time effects $\left(\mathrm{F}_{5,475}=\right.$ $10.0, p=.0002)$. Post-hoc comparisons revealed that ketamine increased scores significantly relative to the placebo test day (drug $\mathrm{X}$ time interaction: $\mathrm{F}_{4,225}=52.8$, $p=.0002)$ and the combination of ketamine and nimodipine (drug $\mathrm{X}$ time interaction: $\mathrm{F}_{4,225}=7.2, p=.0002$ ).

Euphoria. As measured by the visual analog scale measuring "high", ketamine produced euphoric effects that were attenuated by nimodipine (Figure 2). The mixed regression model applied to these data revealed highly significant interactions of ketamine and time effects $\left(\mathrm{F}_{6,675}=68.4, p=.0003\right)$, nimodipine and time effects $\left(\mathrm{F}_{6,675}=2.9, p=.03\right)$, and ketamine, nimodipine and time effects $\left(\mathrm{F}_{7,675}=4.2, p=.0003\right)$. Post-hoc comparisons indicated that ketamine increased scores significantly relative to the placebo test day (drug $X$ time interaction: $\left.\mathrm{F}_{6,325}=38.6, p=.0002\right)$, and the combination of ketamine and nimodipine (drug $\mathrm{X}$ time interaction: $\left.\mathrm{F}_{6,325}=3.5, p=.004\right)$.

\section{Measures of Cognitive Function}

Verbal Fluency. The number of words produced on each test day was as follows: placebo-placebo: $10.1 \pm$ 0.8 words, placebo-ketamine: $7.6 \pm 0.6$ words, nimodipine-ketamine: $9.9 \pm 0.8$ words, nimodipine-placebo: $12.0 \pm 0.8$ words. The mixed regression model applied to verbal fluency data revealed significant drug effects on this measure $\left(\mathrm{F}_{3,75}=10.2, p=.0002\right)$. Post hoc paired $t$-tests, Bonferroni-adjusted for multiple comparisons, revealed that ketamine reduced fluency relative to all other test days $(p<.05)$, but no other comparisons reached significance. Thus, the reduction in verbal fluency produced by ketamine was attenuated by nimodipine pretreatment, while nimodipine had no effect relative to placebo.

Verbal Learning and Memory. Learning and memory results are presented in Figure 4. The mixed regression model applied to data collected during the three immediate recall trials of the Hopkins Verbal Learning Test (HVLT) revealed that number of repetitions $\left(\mathrm{F}_{2,275}=\right.$ $75.3, p=.0002)$ and nimodipine administration $\left(\mathrm{F}_{1,275}=\right.$ $13.2, p=.0006)$ improved recall scores, while ketamine impaired immediate recall across these trials $\left(\mathrm{F}_{1,275}=\right.$ $105.6, p=.0002)$ in a manner that did not significantly interact with the number of repetitions or with nimodipine. This analysis suggests that the interaction of ketamine and nimodipine effects was additive.

After a 30 min delay, ketamine and nimodipine had additive effects on recall that were independent of the presence of cues intended to enhance memory retrieval. The mixed regression model revealed a facilitatory ef-
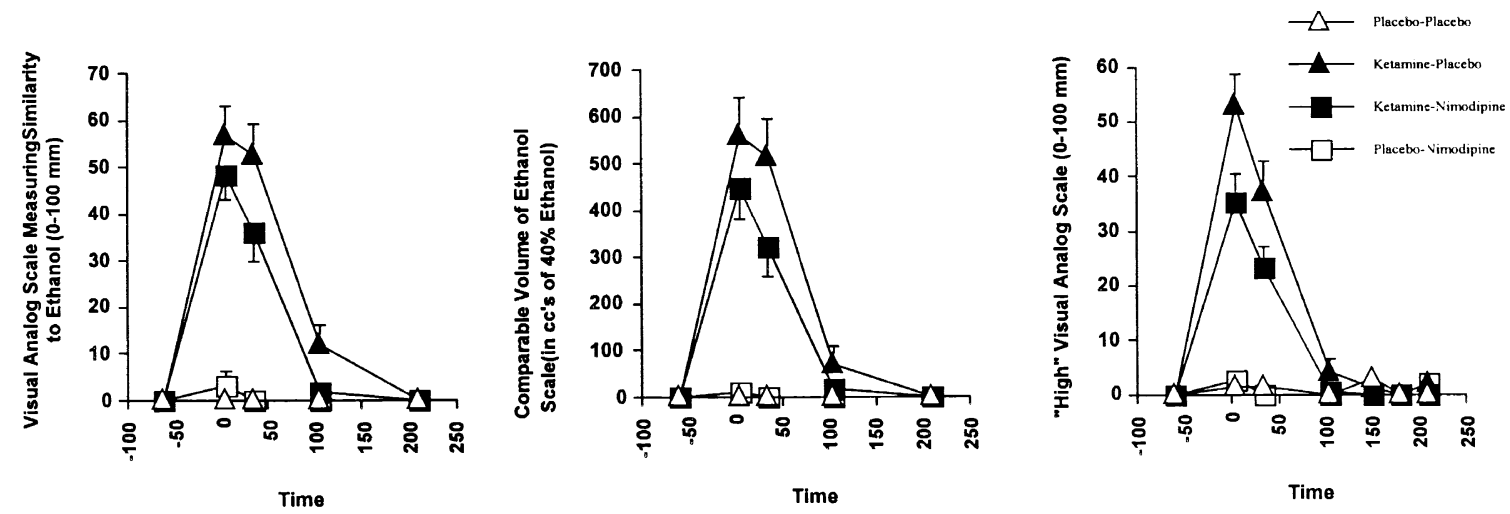

Figure 2. Nimodipine pretreatment partially reduced the degree of similarity of ketamine effects to ethanol effects, intensity of ethanol-like effects of ketamine, and euphoric effects of ketamine in recovering ethanol-dependent patients ( $\mathrm{n}=26)$. Left panel: Visual analog scale (VAS) measuring similarity of behavioral state to ethanol intoxication. Ketamine produced effects that were deemed significantly similar to those of ethanol. The similarity of ketamine effects to ethanol effects was significantly reduced by nimodipine administration. Middle panel: Comparable Volume of Ethanol Scale (CVES). Data reflect the estimated volume of distilled spirits ( $40 \%$ ethanol) that would produce an effect similar to that experienced by the subject. Ketamine significantly increased scores on this subscale. Nimodipine pretreatment reduced significantly ketamine effects on this subscale. Nimodipine had no effects on either subscale. Right panel: VAS measuring "high". The euphoric effects of ketamine were attenuated significantly by pretreatment with nimodipine. Symbols represent mean values \pm standard error of the mean (SEM). Statistical analyses are presented in the text. 

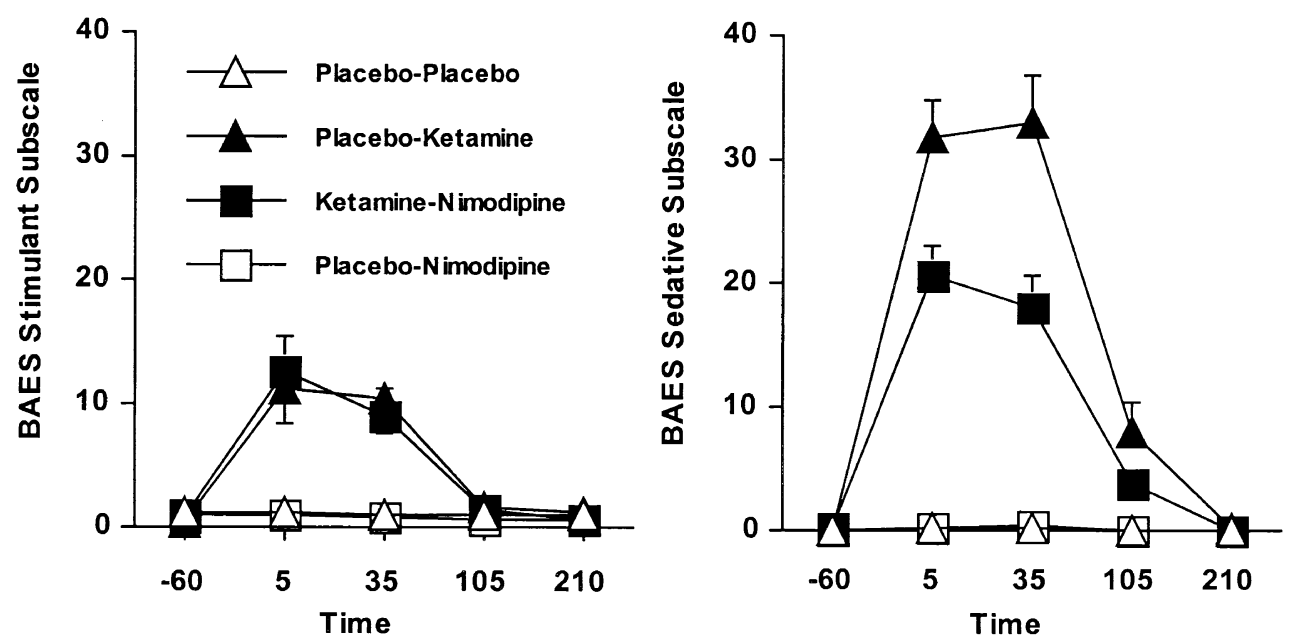

Figure 3. Differential interactive effects of nimodipine and ketamine upon the stimulant and sedative subscales of the Biphasic Alcohol Effects Scale (BAES) in recovering ethanol-dependent patients $(n=26)$. Left panel: Stimulant Subscale of the BAES. Ketamine significantly increased scores on this subscale and this effect was not altered by nimodipine pretreatment. Right panel: Sedative Subscale of the BAES. Ketamine significantly increased scores on this subscale. Nimodipine pretreatment reduced significantly ketamine effects on this subscale. Nimodipine had no effects on either subscale. Data presented represent mean data \pm standard error of the mean (SEM). Statistical analyses are presented in the text.

fect of nimodipine $\left(\mathrm{F}_{1,175}=10.8, p=.002\right)$ and a disruptive effect of ketamine $\left(\mathrm{F}_{1,175}=82.7, p=.0002\right)$. The presence of cues consisting of item categories improved the retrieval of encoded information relative to free recall $\left(\mathrm{F}_{1,175}=12.3, p=.001\right)$. However, there was no significant interaction of ketamine, nimodipine, and cues. Similarly, subjects could recognize more items than they could recall $\left(\mathrm{F}_{1,25}=181.0, p=.0001\right)$. However, there were no significant drug effects on recognition. These findings may suggest that each drug influenced memory encoding rather than memory retrieval.

\section{Physiologic Measures}

Blood Pressure Analysis of blood pressure data confirmed that ketamine increased blood pressure, nimodipine reduced blood pressure, and that these drugs had additive interactive effects (Figure 5). The random effects model applied to the systolic blood pressure data revealed significant effects of ketamine $\left(\mathrm{F}_{1,775}=36.0, p=\right.$ $.0003)$, nimodipine $\left(\mathrm{F}_{1,775}=7.9, p=.02\right)$, time $\left(\mathrm{F}_{7,775}=\right.$ $4.0, p=.0009)$. The interaction of ketamine and time was significant $\left(\mathrm{F}_{7,775}=5.1, p=.0003\right)$, but no other interactions reached significance. The random effects model applied to the diastolic blood pressure data found significant effects of ketamine $\left(\mathrm{F}_{1,775}=9.3, p=.0003\right)$, nimodipine $\left(\mathrm{F}_{1,775}=\right.$ $7.9, p=.02)$, time $\left(\mathrm{F}_{7,775}=8.6, p=.0003\right)$. The interaction of ketamine and time was significant $\left(\mathrm{F}_{7,775}=6.5, p=.0003\right)$, but no other interactions reached significance.
Pulse The analysis of heart rate data, depicted in Figure 5, indicated that ketamine $\left(\mathrm{F}_{1,775}=45.4, p=.0003\right)$ and time $\left(\mathrm{F}_{7,775}=4.0, p=.0009\right)$, but not nimodipine, had significant effects. Post-hoc analyses described differences between the placebo-placebo and the placeboketamine (drug effect: $F_{1,375}=15.9, p=.0004$ ) and the nimodipine-ketamine (drug effect: $\mathrm{F}_{1,375}=51.4, p=$ $.0004)$ test days.

\section{DISCUSSION}

The principal finding of this study was that pretreatment with the L-type VSCC antagonist, nimodipine, attenuated the subjective and cognitive effects the NMDA antagonist, ketamine, in ethanol dependent inpatients who had been sober for over one month. Ketamine produced positive and negative symptoms in these recovering ethanol-dependent patients as measured by the BPRS, perceptual changes as measured by the CADSS, and dysphoric mood as reflected in the Anxious-Depression Factor items of the BPRS. Each of these symptom clusters was attenuated by nimodipine pretreatment. In this patient group, the subjective effects produced by ketamine administration were judged to resemble the subjective effects associated with ethanol intoxication. The intensity of the ethanol-like effects of ketamine in this study approached the level of subjective intoxication that they 
associated with the ingestion of approximately $600 \mathrm{cc}$ of $40 \%$ ethanol, a level of intoxication common for this patient group. The degree of similarity of ketamine effects to the effects of ethanol, as measured by the VAS assessing similarity to ethanol effects, the intensity of ethanol intoxication as assessed by the CVES and BAES sedative subscale, and the degree of euphoria produced by ketamine were reduced by nimodipine pretreatment. In clear contrast to the other outcomes, the stimulant effects of ketamine, as measured by the BAES stimulant subscale score, were not reduced by nimodipine pretreatment. In the cognitive sphere, ketamine reduced immediate, delayed, and cued recall, while nimodipine modestly improved all of these measures under conditions of both active and placebo ketamine administration. Nimodipine also decreased ketamine impairment of verbal fluency.

The capacity of nimodipine to attenuate ketamineinduced positive and negative symptoms of psychosis or the perceptual alterations associated with dissociative

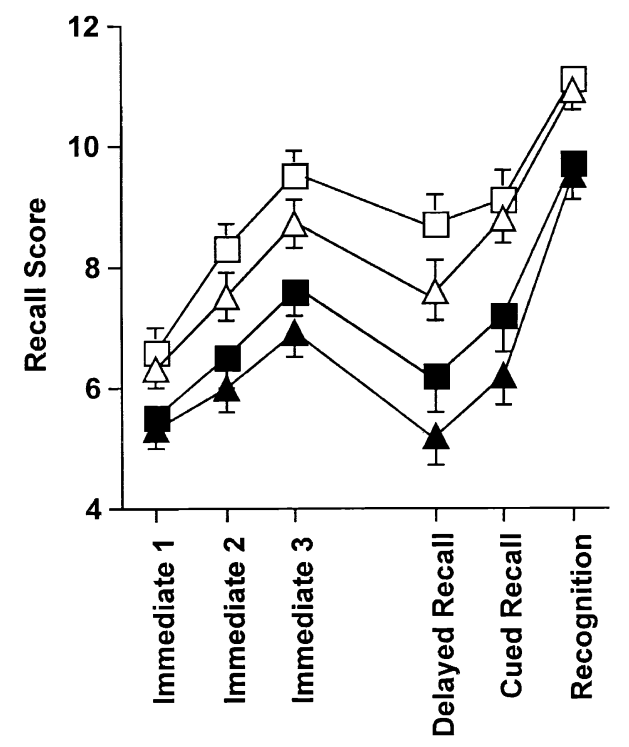

Assessment

Figure 4. Interactive effects of nimodipine and ketamine upon performance of the Hopkins Verbal Learning Test in recovering ethanol-dependent patients $(n=26)$. Symbols represent mean values \pm SEM: open triangle: placebo-placebo test day, filled triangle: placebo-ketamine test day, filled square: nimodipine-ketamine test day, open square: nimodipine-placebo test day. In the analysis, both nimodipine significantly improved recall scores when administered prior to placebo and ketamine. Ketamine significantly worsened recall scores when administered following nimodipine and placebo. However, the interaction of these drugs was not significant. Also, there were significant effects of number of repetitions, delay, and type of retrieval (cued, non-cued), but these effects did not interact significantly with drug effects. Statistical analyses are presented in the text. states lends supports to its further pharmacotherapeutic evaluation in psychiatric disorders. The current data replicate previous research indicating that ketamine produces positive and negative symptoms and perceptual effects in non-psychotic populations (Krystal et al. 1994a; Malhotra et al. 1996; Newcomer et al. 1999; Vollenweider et al. 1997). In clinical trials, nimodipine has shown promise in treating bipolar disorder, although it has had inconsistent effects in schizophrenic patients (Post 1999). Nimodipine has yet to be evaluated in post-traumatic stress disorder or other dissociative disorders.

Nimodipine attenuated components of the ethanollike effects of ketamine. The fact that nimodipine reduced the similarity to ketamine without attenuating its stimulant effects suggests that the sedative effects of ketamine figure prominently in the reported ethanollike effects of this drug. The failure of nimodipine to attenuate stimulant effects of ketamine in humans contrasts with the ability of nimodipine pretreatment to reduce the psychomotor stimulant effects of ketamine in mice. Perhaps this difference is related to the greater stimulant effects of subanesthetic ketamine in mice relative to humans (Uchihashi et al. 1992). The current study replicated the subjective similarity of ketamine effects to ethanol in ethanol-dependent patients despite using a different ketamine infusion paradigm than the earlier study (Krystal et al. 1998b). Consistent with the more rapid rise in ketamine blood levels and higher plasma ketamine levels associated with the current bolus and constant infusion paradigm relative to the previous slow infusion study (Krystal et al. 1998a), the ethanol-like effects of ketamine were judged to be more intense on the CVES relative to the prior study. Nimodipine had no significant ethanol-like effects in this study. This finding contrasts with reports of ethanollike discriminative properties of nimodipine in ethanolexperienced animals (De Beun et al. 1996; De Vry et al. 1999; Green and Grant 1999).

However, this study failed to demonstrate that nimodipine pretreatment enhanced the perceived similarity of ketamine effects to ethanol effects. Ethanol blocks both L-type VSCCs and NMDA receptors (Crews et al. 1996) and it has relatively less propensity to produce psychosis and perceptual alterations than ketamine. In this study, nimodipine pretreatment preserved aspects of the stimulant effects of ketamine, while nimodipine attenuated the propensity of ketamine to produce psychosis or perceptual alterations. These alterations in the subjective effects of ketamine were predicted to produce a perception that ketamine had become more ethanol-like, consistent with some preclinical research findings (Green-Jordan and Grant 2000). Instead, nimodipine primarily attenuated ethanol-like effects and other subjective effects produced by ketamine. This result may have been consistent with preclinical evidence of reduction in the discriminative stimulus effects of di- 

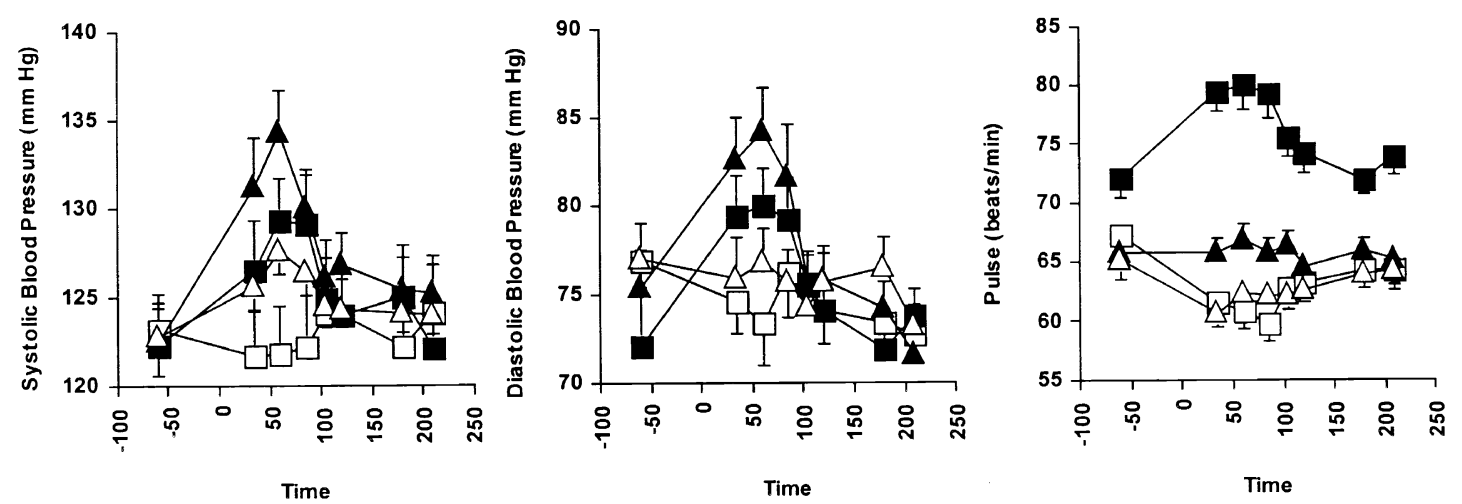

Figure 5. Interactive effects of nimodipine and ketamine upon blood pressure and pulse in recovering ethanol-dependent patients $(n=26)$. Left panel: Systolic blood pressure. Analysis revealed significant effects of ketamine, nimodipine, and time, but no significant interactions between ketamine and nimodipine effects. Middle panel: Diastolic blood pressure. Analysis revealed significant ketamine, nimodipine, and time effects, but no significant interactions between ketamine and nimodipine effects. Right panel: Pulse. Analysis revealed a significant ketamine by time interaction, but no significant nimodipine effect. Symbols represent mean values \pm SEM: open triangle: placebo-placebo test day, filled triangle: placebo-ketamine test day, filled square: nimodipine-ketamine test day, open square: nimodipine-placebo test day. Statistical analyses are presented in the text.

zocilpine by nimodipine in animals (Sukhotina et al. 1999). To the extent that the current data provide insight into mechanisms of ethanol reward, they may provide insight into the capacity of nimodipine to attenuate ethanol self-administration in animals (Kuzmin et al. 1999).

Nimodipine improved memory function in this group of recovering ethanol dependent patients, a group with a high prevalence of cognitive impairment (Parsons and Nixon 1993). In healthy animals, nimodipine may impair learning (Maurice et al. 1995). However, nootropic effects of nimodipine have been previously demonstrated in other neuropsychiatric disorders (Pantoni et al. 1996; Sze et al. 1998), aged animals (Levere and Walker 1992; Sandin et al. 1990) and animals with anticholinergic impairments in learning (Balakrishnan and Pandhi 1997). In preclinical studies, sustained nimodipine administration enhanced spatial learning without promoting long-term potentiation (Kane and Robinson 1999). It is possible that non-specific factors contributed to the nootropic effects of nimodipine in this study. However, nimodipine did not influence mood, arousal, verbal fluency, or the level of ethanol withdrawal symptoms relative to placebo. Thus, the current data support the evaluation of nimodipine in the treatment of memory dysfunction in recovering ethanol dependent patients.

This study provides limited insight into the mechanisms underlying the capacity of nimodipine to attenuate ketamine effects, yet the inferences that one might draw from the current data are highly dependent upon this knowledge. One limitation of the current study was its failure to measure plasma level of ketamine, nimodipine, and their metabolites. Thus, one cannot establish whether plasma ketamine levels were steady or chang- ing throughout the study. In addition, one cannot rule out pharmacokinetic interactions between nimodipine and ketamine. Nimodipine does not appear to have clear effects on hepatic microsomal enzymes, while ketamine modestly inhibits cytochrome CYP3A (Meneguz et al. 1999). As a result, the absence of a potentiation of nimodipine effects by ketamine questions the importance of pharmacokinetic interactions in this study. A second possibility is that nimodipine modulated NMDA receptor function making NMDA receptors less available to ketamine blockade. Nimodipine, for example, reduces membrane depolarization through blockade of L-type VSCCs and, to a lesser extent, voltage-gated sodium channels (Monjaraz et al. 2000). This effect would be predicted to reduce the number of NMDA receptors in the activated state (Yu and Salter 1998). Alternatively, perhaps by attenuating intracellular calcium levels, nimodipine may have influenced the phosphorylation state of NMDA receptor subunits and reduced the ketamine sensitivity of these receptors (Zhang et al. 1998). A third possibility is that nimodipine and ketamine interacted through opposing modulation of the function of intracellular phosphoproteins, such as calmodulin or cAMP response element-binding protein, whose function might be directly or indireclty sensitive to calcium (CREB) (Deisseroth et al. 1998; Ghosh et al. 1994; Mermelstein et al. 2000). These direct interactions might have been detected as a generalized rightward shift in the dose-response relationship for ketamine. However, the current study was limited to a single dose of ketamine. Thus, the current study cannot confirm or refute the existance of these types of interactions.

An additional possible explanation for the current findings is that nimodipine attenuated the hyperglutamatergic 
effects of ketamine without normalizing NMDA receptor function (Krystal et al. 1999a). Ketamine appears to disinhibit cortical glutamatergic activity (Grunze et al. 1996; Moghaddam et al. 1997). It is possible that nimodipine attenuated glutamate release or its postsynaptic consequences (Schiller et al. 1998; Segal 1995; Yuste et al. 1999). From this perspective, one would have predicted that nimodipine would reduced only those behavioral effects of ketamine dependent on its capacity to stimulate glutamate release, but not behavioral effects arising directly from reduction of NMDA receptor function. However, this study and a previous study of a drug known to attenuate glutamate release (Anand et al. 2000; Langosch et al. 2000) suggest that voltage-gated cation channel antagonists attenuate the perceptual and amnestic effects of ketamine without reducing its stimulant effects. Preclinical reports suggest that the rewarding or stimulating effects of NMDA antagonists reflect blockade of NMDA receptors postsynaptic to corticofugal projections to limbic regions, such as the nucleus accumbens (Carlezon and Wise 1996a; Carlezon and Wise 1996b; Gracy et al. 1997). If so, then the current findings may suggest that a component of the interactive effects observed in this study reflect a reduction in the hyperglutamatergic effects of ketamine by nimodipine pretreatment.

In conclusion, the current study identified a number of striking interactions between drugs that attenuate the neuronal entry of calcium through two distinct mechanisms. Across many cognitive and behavioral measures, the L-type VSCC blocker, nimodipine, reduced the effects of the NMDA glutamate receptor antagonist, ketamine. Nimodipine had this impact on ketamine response despite showing nootropic activity, but no other intrinsic behavioral effects. As a result, this study may serve to raise interest in the interplay of ligand and voltage-gated calcium channels in the pathophysiology and treatment of neuropsychiatric and addiction disorders.

\section{ACKNOWLEDGMENTS}

This study was designed with support of the Fogarty Foundation. It was carried out with support from the Civilian Research Development Foundation and from the U.S. Department of Veterans Affairs (Alcohol Research Center: J.K., I.P.), and the National Institute of Alcohol Abuse and Alcoholism KO2 AA 00261-01 (J.K.)

\section{REFERENCES}

Anand A, Charney DS, Cappiello A, Berman RM, Oren DA, Krystal JH (2000): Lamotrigine attenuates ketamine effects in humans: support for hyperglutamatergic effects of NMDA antagonists. Archives of General Psychiatry 57:270-276
Balakrishnan S, Pandhi P (1997): Effect of nimodipine on the cognitive dysfunction induced by phenytoin and valproate in rats. Methods \& Findings in Experimental \& Clinical Pharmacology 19:693-697

Borkowski JG, Benton AL, Spreen O (1967): Word fluency and brain damage. Neuropsychologia 5:135-140

Brandt J (1991): The Hopkins Verbal Learning Test: development of a new memory test with six equivalent forms. The Clinical Neuropsychologist 5:125-142

Bremner JD, Krystal JH, Putnam FW, Southwick SM, Marmar C, Charney DS, Mazure CM (1998): Measurement of dissociative states with the Clinician-Administered Dissociative States Scale (CADSS). Journal of Traumatic Stress 11:125-136

Carcas AJ, Abad-Santos F, de Rosendo JM, Frias J (1996): Nimodipine transfer into human breast milk and cerebrospinal fluid. Annals of Pharmacotherapy 30:148-150

Carlezon Jr WA, Wise RA (1996a): Microinjections of phencyclidine (PCP) and related drugs into nucleus accumbens shell potentiate medial forebrain bundle brain stimulation reward. Psychopharmacology 128:413-420

Carlezon Jr WA, Wise RA (1996b): Rewarding actions of phencyclidine and related drugs in nucleus accumbens shell and frontal cortex. Journal of Neuroscience 16:3112-3122

Crews FT, Morrow AL, Criswell H, Breese G (1996): Effects of ethanol on ion channels. International Review of Neurobiology 39:283-367

De Beun R, Lohmann A, Schneider R, De Vry J (1996): Comparison of the stimulus properties of ethanol and the $\mathrm{Ca} 2+$ channel antagonist nimodipine in rats. Eur J Pharmacol 306:5-13

De Vry J, Schreiber R, De Beun R (1999): Discriminative and affective stimulus effects of dihydropyridine calcium channel modulators: relationship to antialcohol effects. Pharmacology Biochemistry \& Behavior 64:203-211

Deisseroth K, Heist EK, Tsien RW (1998): Translocation of calmodulin to the nucleus supports CREB phosphorylation in hippocampal neurons. Nature 392:198-202

Ghosh A, Ginty DD, Bading H, Greenberg ME (1994): Calcium regulation of gene expression in neuronal cells. J Neurobiol 25:294-303

Gracy KN, Svingos AL, Pickel VM (1997): Dual ultrastructural localization of mu-opioid receptors and NMDAtype glutamate receptors in the shell of the rat nucleus accumbens. Journal of Neuroscience 17:4839-4848

Grant KA, Colombo G (1993): Discriminative stimulus effects of ethanol: effect of training dose on the substitution of N-methyl-D-aspartate antagonists. Journal of Pharmacology \& Experimental Therapeutics 264:12411247

Grant KA, Lovinger DM (1995): Cellular and behavioral neurobiology of alcohol: receptor-mediated neuronal processes. Clin Neurosci 3:155-164

Green KL, Grant KA (1998): Evidence for overshadowing by components of the heterogeneous discriminative stimulus effects of ethanol. Drug \& Alcohol Dependence 52:149-159

Green KL, Grant KA (1999): Effects of L-type voltage-sensitive calcium channel modulators on the discriminative stimulus effects of ethanol in rats. Alcoholism Clinical \& Experimental Research 23:806-814 
Green-Jordan K, Grant KA (2000): Modulation of the ethanol-like discriminative stimulus effects of diazepam and phencyclidine by L-type voltage-gated calciumchannel ligands in rats. Psychopharmacology 149:84-92

Grunze HC, Rainnie DG, Hasselmo ME, Barkai E, Hearn EF, McCarley RW, Greene RW (1996): NMDA-dependent modulation of CA1 local circuit inhibition. Journal of Neuroscience 16:2034-2043

Hedlund JL, Vieweg BW (1980): The Brief Psychiatric Rating Scale (BPRS): a comprehensive review. Journal of Operational Psychiatry 11:48-64

Kane KA, Robinson GB (1999): Effect of chronic nimodipine on spatial learning and on long-term potentiation. Behavioural Brain Res 98:95-101

Krystal JH, Belger A, D'Souza DC, Anand A, Charney DS, Aghajanian GK, Moghaddam B (1999a): Therapeutic implications of the hyperglutamatergic effects of NMDA antagonists. Neuropsycohpharmacology 22:S143-S157

Krystal JH, D'Souza DC, Karper LP, Bennett A, AbiDargham A, Abi-Saab D, Bowers MB Jr, Jatlow P, Heninger GR, Charney DS (1999b): Interactive effects of subanesthetic ketamine and haloperidol. Psychopharmacology 145:193-204

Krystal JH, D'Souza DC, Petrakis IL, Belger A, Berman R, Charney DS, Abi-Saab W, Madonick S (1999c): NMDA agonists and antagonists as probes of glutamatergic dysfunction and pharmacotherapies for neuropsychiatric disorders. Harvard Review of Psychiatry 7:125-133

Krystal JH, Karper LP, Bennett A, D'Souza DC, AbiDargham A, Morrissey K, Abi-Saab D, Bremner JD, Bowers MB Jr, Suckow RF, Stetson P, Heninger GR, Charney DS (1998a): Interactive effects of subanesthetic ketamine and subhypnotic lorazepam in humans. Psychopharmacology 135:213-229

Krystal JH, Karper LP, Seibyl JP, Freeman GK, Delaney R, Bremner JD, Heninger GR, Bowers MB Jr, Charney DS (1994a): Subanesthetic effects of the noncompetitive NMDA antagonist, ketamine, in humans. Psychotomimetic, perceptual, cognitive, and neuroendocrine responses. Arch Gen Psychiatry 51:199-214

Krystal JH, Petrakis IL, Webb E, Cooney NL, Karper LP, Namanworth S, Stetson P, Trevisan LA, Charney DS (1998b): Dose-related ethanol-like effects of the NMDA antagonist, ketamine, in recently detoxified alcoholics. Archives of General Psychiatry 55:354-360

Krystal JH, Webb E, Cooney N, Kranzler HR, Charney DS (1994b): Specificity of ethanollike effects elicited by serotonergic and noradrenergic mechanisms. Archives of General Psychiatry 51:898-911

Kuzmin A, Semenova S, Zvartau E, De Vry J (1999): Effects of calcium channel blockade on intravenous self-administration of ethanol in rats. European Neuropsychopharmacology 9:197-203

Langosch JM, Zhou XY, Frick A, Grunze H, Walden J (2000): Effects of lamotrigine on field potentials and long-term potentiation in guinea pig hippocampal slices. Epilepsia 41:1102-1106

Levere TE, Walker A (1992): Old age and cognition: enhancement of recent memory in aged rats by the calcium channel blocker nimodipine. Neurobiology of Aging 13:63-66
Lovinger DM (1997): Alcohols and neurotransmitter gated ion channels: past, present and future. NaunynSchmiedebergs Archives of Pharmacology 356:267-282

Luby ED, Cohen BD, Rosenbaum G, Gottlieb JS, Kelley R (1959): Study of a new schizophrenomimetic drug-sernyl. Arch Neurol Psychiatry 81:363-369

Malhotra AK, Pinals DA, Weingartner H, Sirocco K, Missar CD, Pickar D, Breier A (1996): NMDA receptor function and human cognition: the effects of ketamine in healthy volunteers. Neuropsychopharmacology 14:301-307

Martin CS, Earleywine M, Musty RE, Perrine MW, Swift RM (1993): Development and validation of the Biphasic Alcohol Effects Scale. Alcoholism Clinical \& Experimental Research 17:140-146

Maurice T, Su TP, Parish DW, Privat A (1995): Prevention of nimodipine-induced impairment of learning by the selective sigma ligand PRE-084. Journal of Neural Transmission-General Section 102:1-18

Meneguz A, Fortuna S, Lorenzini P, Volpe MT (1999): Influence of urethane and ketamine on rat hepatic cytochrome P450 in vivo. Experimental \& Toxicologic Pathology 51:392-396

Mermelstein PG, Bito H, Deisseroth K, Tsien RW (2000): Critical dependence of cAMP response element-binding protein phosphorylation on L-type calcium channels supports a selective response to EPSPs in preference to action potentials. Journal of Neuroscience 20:266-273

Moghaddam B, Adams B, Verma A, Daly D (1997): Activation of glutamatergic neurotransmission by ketamine: a novel step in the pathway from NMDA receptor blockade to dopaminergic and cognitive disruptions associated with the prefrontal cortex. J Neurosci 17:2921-2927

Monjaraz E, Navarrete A, Lopez-Santiago LF, Vega AV, Arias-Montano JA, Cota G (2000): L-type calcium channel activity regulates sodium channel levels in rat pituitary GH3 cells. J Physiol 523:45-55

Newcomer JW, Farber NB, Jevtovic-Todorovic V, Selke G, Kelly Melson A, Hershey T, Craft S, Olney JW (1999): Ketamine-induced NMDA receptor hypofunction as model of memory impairment and psychosis. Neuropsychopharmacology 20:106-118

Overall JE, Gorham DR (1962): The Brief Psychiatry Rating Scale. Psychol Rep 10:799-812

Pantoni L, Carosi M, Amigoni S, Mascalchi M, Inzitari D (1996): A preliminary open trial with nimodipine in patients with cognitive impairment and leukoaraiosis. Clinical Neuropharmacology 19:497-506

Parsons OA, Nixon SJ (1993): Neurobehavioral sequelae of alcoholism. Neurologic Clinics 11:205-218

Petrakis IL, Lemoncelli D, Trevisan L, Boutros NN, Gelernter J, Krystal JH (2001): Altered NMDA antagonist responses associated with familial alcoholism vulnerability and ethanol dependence in humans: possible therapeutic implications. Biological Psychiatry 49:77S

Popoli P, Pezzola A, Benedetti M, Scotti de Carolis A (1992): Verapamil and flunarizine inhibit phencyclidineinduced effects: an EEG and behavioural study in rats. Neuropharmacology 31:1185-1191

Post RM (1999): Comparative pharmacology of bipolar disorder and schizophrenia. Schizophrenia Research 39: 153-158 
Sandin M, Jasmin S, Levere TE (1990): Aging and cognition: facilitation of recent memory in aged nonhuman primates by nimodipine. Neurobiology of Aging 11:573-575

Schiller J, Schiller Y, Clapham DE (1998): NMDA receptors amplify calcium influx into dendritic spines during associative pre- and postsynaptic activation. Nat Neurosci 1:114-118

Segal M (1995): Imaging of calcium variations in living dendritic spines of cultured rat hippocampal neurons. J Physiol 486:283-295

Sukhotina IA, Dravolina OA, Medvedev IO, Bespalov AY (1999): Effects of calcium channel blockers on behaviors induced by the N-methyl-D-aspartate receptor antagonist, dizocilpine, in rats. Pharmacology Biochemistry \& Behavior 63:569-580

Sze KH, Sim TC, Wong E, Cheng S, Woo J (1998): Effect of nimodipine on memory after cerebral infarction. Acta Neurologica Scandinavica 97:386-392

Uchihashi Y, Kuribara H, Tadokoro S (1992): Assessment of the ambulation-increasing effect of ketamine by coadministration with central-acting drugs in mice. Japanese Journal of Pharmacology 60:25-31

Vollenweider FX, Leenders KL, Scharfetter C, Antonini A, Maguire P, Missimer J, Angst J (1997): Metabolic hyperfrontality and psychopathology in the ketamine model of psychosis using positron emission tomography (PET) and [18F]fluorodeoxyglucose (FDG). European Neuropsychopharmacology 7:9-24

Yu XM, Salter MW (1998): Gain control of NMDA-receptor currents by intracellular sodium. Nature 396:469-474

Yuste R, Majewska A, Cash SS, Denk W (1999): Mechanisms of calcium influx into hippocampal spines: heterogeneity among spines, coincidence detection by NMDA receptors, and optical quantal analysis. Journal of Neuroscience 196:1976-1987

Zhang S, Ehlers MD, Bernhardt JP, Su CT, Huganir RL (1998): Calmodulin mediates calcium-dependent inactivation of N-methyl-D-aspartate receptors. Neuron 21:443-453 